\title{
Investment appraisal and the choice between continuous and discrete cash flow discounting
}

Luiz Ricardo Cavalcante ${ }^{1}$

Carlos Henrique Rocha ${ }^{2}$
$1 \mathrm{PhD}$ em Administração de Empresas. Consultor do Senado Federal. Professor do Mestrado em Administração Pública do

Instituto Brasiliense de Direito Público. luiz.ricardo.teixeira.cavalcante@gmail.com

2 Faculdade de Administração, Contabilidade e Economia (FACE) da UnB. Departamento de Ciências Contábeis e Atuarias (CCA). Professor Associado III. chrocha@unb.br

\section{Abstract}

The vast majority of corporate finance textbooks presents the problem of investment decisions considering discrete cash flows at the end of each period. However, on several occasions, this assumption does not fit the facts, as in the case of the revenues of large retailers, which tend to be generated almost continuously, instead of at the end of each year. In this paper, we compare the net present value of a typical investment considering both a discrete distribution of expected cash flows and a continuous one. We show that the differences observed depend upon the behavior of the function that describes the cash flows and upon the capital cost used to discount the values. Differences tend to be higher if higher capital costs are used. As a result, riskier projects are more sensitive to the right choice of the cash flow distribution to be used in its appraisal and no method can be considered, $a$ priori, better than the other, as operational, fiscal and accounting aspects may make continuous or discrete cash flows more appropriate to describe practical realities. Thus, the article contributes to better supporting investment decisions and to enriching teaching material addressing the subject of investment decisions.

Keywords: Present value. Continuous and discrete cash flows. Distribution of continuous cash flows. Investment appraisal. 


\section{Introduction}

The aim of investment decisions is to identify real assets whose value is higher than their cost of acquisition. Asset evaluation usually involves the calculation of the net present value (NPV) which is the difference between the present value of the cash flows the asset is expected to generate and the present value of the cost of asset acquisition. According to Jones and Smith (1982), the first reference to NPV in the American economic literature appeared in 1907 in Irving Fisher's “The Rate of Interest”. Ever since then, NPV is one of the most important concepts in finance (Brealey \& Myers, 1988; Ross, Westerfield, \& Jaffe, Jeffrey 1995). It is considered the most reliable method for capital budgeting decision-making as it takes into account a given investment's incremental cash flows discounted considering their magnitude, timing, and risk. NPV is a measure of how much value is created or added by undertaking a given investment. Cash flows are usually discounted by the weighted average capital cost, which takes into account the risk-free rate as well as a risk premium associated to the investment.

In spite of the controversies about its rigidity - especially the ones associated to the Real Options Theory - and about the calculation of the capital cost to be used to discount the future cash flows associated to the project, NPV remains, undoubtedly, the most robust criterion of investment appraisal. In general, it relies on the assumption of discrete cash flows at the end of each period, and most corporate finance textbooks (Ross et al., 1995; Brigham \& Houston, 2004; Damodaran, 1998; Gitman, 1997) barely mention the possibility that cash flows might be continuously distributed during the investment's lifetime.

However, on several occasions, the assumption of discrete cash flows at the end of each pe- riod does not fit the facts. Revenues of large retailers, for example, tend to be generated almost continuously, instead of at the end of each year. In some cases, cash flows are unevenly distributed inside each period. As we show in this paper, assuming that these cash flows are simply concentrated at the end of each period may lead to significant differences in NPV (especially when discount rates are higher) and, as result, to bad investment decisions.

In order to better support investment decisions in cases such as the ones mentioned above, as well as to enrich teaching material addressing the subject of investment decisions, we discuss, in this paper, the calculation of the present value of continuous cash flows and we compare the obtained results to the ones obtained according to the discrete cash flows approach. The paper is structured in four additional sections besides this introduction. Section 2 reviews previous works that have dealt with continuous distribution of cash flows. The third section presents the models adopted in this paper. Three types of distribution of continuous cash flows inside each period are considered: i) expected cash flows are equivalent to an annuity, ii) expected cash flows are equivalent to an annuity and have a linear distribution pattern over time; and iii) expected cash flows are equivalent to an annuity but have a seasonal distribution pattern. The results obtained for each of these types are compared with the results obtained under the discrete cash flows assumption in section 4. As shown in the literature review, the use of different patterns of cash flow distribution is a theoretical contribution of this paper, as previous works focus only on a single functional form to describe the behavior of continuous cash flows inside each period. Finally, section 5 highlights the main conclusions of this paper. 


\section{Literature review}

There is a relatively low number of papers aiming at appraising investments under the continuous cash flow assumption. Corporate finance textbooks - like the ones mentioned in the introduction of this paper - systematically consider that cash flows occur discretely at the end of each period. Just a few specific textbooks such as "An introduction to the mathematics of finance" (Garrett, 2013) seem to cope with continuous cash flow distribution. That might be a result of purely didactic concerns, as discrete cash flow discounting is certainly easier to understand and compute. Besides, assuming that positive cash flows concentrate at the end of each period - instead of spreading over the entire period - usually (but not always, as shown in this paper) leads to more conservative results (i.e., tends to reduce NPV). Pogue (2004), for instance, argues that the assumption of discrete cash flows at the end of each period reduces the likelihood of project acceptance.

More specific discussions as the ones about real options tend to assume the cash flows are continuously distributed, although the implications of this assumption as compared to the more usual one are not the subject of this kind of approach (Dixit \& Pindyck, 1994; Trigeorgis, 1996). On the other hand, Copeland \& Antikarov (2002) argue in favor of the use of expected discrete cash flows in investment decision-making with real options, because their application is more management-friendly. Besides, Chiang \& Wainwright (2006) indicate that, on several occasions, investment appraisal of vineyards and wood chopping farms rely on continuous instead of discrete cash flow distribution.

Specific discussions on the implications of the choice of the discrete or continuous assumptions are relatively scarce. Ismail (1994 apud Ismail \& Cline, 2005) suggest a "refinement of discounted cash flow techniques". According to Ismail and
Cline (2005, p. 33), that work "simplifies the calculation of NPV/IRR models based on continuous discounting factors by deriving a formula based on implicit differentiation".

Pogue (2004) incisively argues in favor of the assumption of continuous cash flows and tries to address "a theoretical weakness inherent in the typical application of the net present value approach to investment appraisal”. Pogue (2004) mentions four previous works to discuss the use of NPV and other capital budgeting methods; however, none of the references mentioned in his work is used to support the discussion about the assumption of continuous or discrete cash flows. Pogue (2004) uses an integration method for continuous (but steady) cash flows and compares the results using discount rates between $1 \%$ and $25 \%$ for periods that range from one to five years. Pogue (2004) takes for granted that all cash flows in fact are continuous and the choice for discrete discounting methods is only a matter of simplicity. In his words, "whilst admittedly managers may face more difficult practical issues in appraising investments, such as the estimation and timing of cash flows, this adjustment could make the difference between accepting and rejecting marginal projects".

Ismail and Cline (2005) present a comprehensive review of previous works that have dealt with continuous discounting of continuous cash flows. According to Ismail \& Cline (2005), Grant \& Ireson (1960 apud Ismail \& Cline, 2005), De La Mare (1975 apud Ismail \& Cline, 2005), Levy \& Sarnat (1978 apud Ismail \& Cline, 2005), Wilkes (1983 apud Ismail \& Cline, 2005) and Ismail (1994 apud Ismail \& Cline, 2005) applied the integration method, while Remer et al. (1984 apud Ismail \& Cline, 2005) used numerical methods and Buck \& Hill (1971 apud Ismail \& Cline, 2005) applied the Laplace transformation method. That leads them to argue that "Pogue's model 
is neither new nor sound". Besides, they argue that "Pogue's model fallaciously uses continuous discounting in the belief that it represents continuous cash flows" (Ismail \& Cline, 2005, p. 31). These authors point out that "the relationship between continuous and discrete models of discounting is unbounded in one direction; i.e. the continuous NPV/IRR may be equal, lower than, or higher than the traditional NPV/IRR" and that "the difference in results between appropriately applied discrete and continuous discounting models does influence the soundness of investment decisions" (Ismail \& Cline, 2005, pp. 33-34).

However clear and comprehensive it may be, Ismail \& Cline's work focuses only on one functional form to describe the behavior of continuous cash flows inside each period (steady flows) and does not discuss the circumstances when continuous or discrete cash flow discounting may be preferable to one another. The remainder of this paper discusses these issues.

\section{Modeling continuous cash flows}

As mentioned in the introduction to this paper, investment appraisal techniques usually rely on the assumption of discrete cash flows at the end of each period. This approach assumes that cash flows associated to each period are, for some reason, concentrated at a single moment at the end of that span of time. Implicitly it is assumed that the cash flow assigned to the end of the period $t$ corresponds to the algebraic sum of all cash flows that are expected to occur within that period (i.e., during the interval between $t-1$ and $t$ ). Thus,

$$
C F_{t}=\sum_{i=t-1}^{t} C F_{i}
$$

This hypothesis can be relaxed as one assumes that cash flows $C F(t)$ are continuously distributed during the total time horizon $T$ of the investment. In order to do that, a function capable of describing the instantaneous cash flow at each moment $t$ is required (Chiang \& Wainwright, 2009). Thus, assuming that the cash flows are discounted at a continuous rate $r(t)$, the present value $P V$ of the project is given by the integral below:

$$
P V=\int_{0}^{T} \frac{C F(t) d t}{[1+r(t)]^{t}}
$$

If the discount rate $r(t)$ is assumed to be constant, equation 2 can be rewritten as follows:

$$
\begin{gathered}
P V=\int_{0}^{T} \frac{C F(t) d t}{(1+r)^{t}} \\
\frac{1}{(1+r)^{t}}=e^{k t} \Rightarrow(1+r)^{-t}=e^{k t} \\
\ln (1+r)^{-t}=\ln e^{k t} \Rightarrow k=-\ln (1+r) \\
P V=\int_{0}^{T} e^{k t} C F(t) d t
\end{gathered}
$$

Where

$$
k=-\ln (1+r)
$$

The result of the integration of equation 3 will obviously depend upon the functional form of the function $C F(t)$. In this paper, the following functional forms have been chosen:

$C F(t)=a_{1}$, where $a_{1}$ is a constant. In this case, the cash flows are assumed to be constant over time.

$C F(t)=a_{1}+a_{2} t$, where $a_{1}$ and $a_{2}$ are two constants. $C F(t)$ is, then, a linear function of $t$. This is clearly an extension of the first functional form, as if $a_{2}=0, C F(t)$ is constant over time; and 
$C F(t)=a_{1}+a_{2} \sin \left[a_{3}\left(t+a_{4}\right)\right]$, where $a_{1}, a_{2}$, $a_{3}$ e $a_{4}$ are four constants. This functional form reflects a seasonal pattern of cash flow distribution. In this case, instantaneous cash flows preset a maximum and a minimum value in each period. This is typically the case of investments with higher cash flows in a given moment of the year due to climate or cultural reasons (e.g., vineyards or Easter eggs manufactures, as a "stylized example").

The functional forms selected for $C F(t)$ are indicated in Graph 1 below.

It must be noted that the coefficients have, in each case, a practical meaning. In the first case (constant cash flows), it is just the cash flow associated to each period. In the second case, $a_{1}$ and $a_{2}$ are, respectively, the linear and angular coefficients of a first grade polynomial function. Naturally, if $a_{2}>0$, cash flows increase during the time spam $T$; if $a_{2}<0$, cash flows decrease and if $a_{2}=0$ cash flows are constant and the second functional forms reduce to the first one. Finally, in the case of seasonal cash flows, $a_{1}$ is the level around which the flows move forward, $a_{2}$ is the oscillation amplitude, $a_{3}$ is a constant used to convert values to radians and $a_{4}$ is the lag compared to a sine function used as a reference. If $a_{4}=0$, for example, the function assumes the value $a_{1}$ for $\mathrm{t}=$ 0 ; if $a_{4}=0.5$ the function is moved forward half a period and becomes similar to a cosine function.

In the following subsections, the integration of equation 3 is algebraically solved for the three functional forms proposed above.

\subsection{Constant Cash Flows}

Assuming that $C F(t)=a_{1}$, where $a_{1}$ is a constant, equation 3 takes the format below:

$$
P V=\int_{0}^{T} e^{k t} a_{1} d t
$$

The result of the integral above is given by equation 6 below (see Spiegel \& Liu, 1999, p. 85, equation 14.509):

$$
P V=\left(\frac{a_{1} e^{k t}}{k}\right)_{t=T}-\left(\frac{a_{1} e^{k t}}{k}\right)_{t=0}
$$

\subsection{Linear Cash Flows}

Now assuming that the cash flows have an increasing (or decreasing) trend during the period (i.e., assuming that $C F(t)=a_{1}+a_{2} t$, where $a_{1}$ and
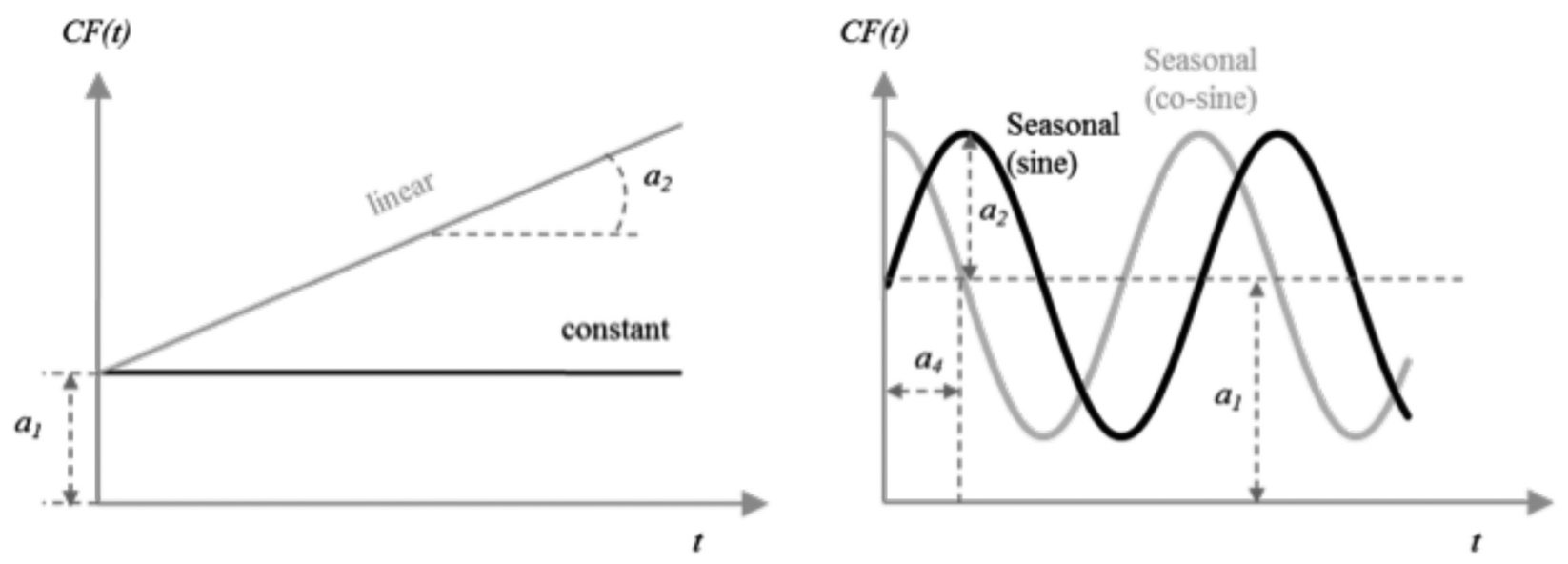
$a_{2}$ are constant) the present value $P V$ can be calculated integrating the expression below:

$$
P V=\int_{0}^{T} e^{k t}\left(a_{1}+a_{2} t\right) d t
$$

The integral indicated in equation 7 can be segmented in two parts as shown below:

$$
P V=P V_{1}+P V_{2}=\int_{0}^{T} e^{k t} a_{1} d t+\int_{0}^{T} e^{k t} a_{2} t d t
$$

The first part $\left(P V_{1}\right)$ can be calculated following the procedures indicated in subsection 3.1 above. Thus,

$$
P V_{1}=\left(\frac{a_{1} e^{k t}}{k}\right)_{t=T}-\left(\frac{a_{1} e^{k t}}{k}\right)_{t=0}
$$

The second part $\left(P V_{2}\right)$ is given by equation 10 below:

$$
P V_{2}=\int_{0}^{T} e^{k t} a_{2} t d t=a_{2} \int_{0}^{T} t e^{k t} d t
$$

The outcome of this integral is given by equation 12 below (see SPIEGEL; LIU, 1999, p. 85, eq. 14.510):

$$
P V_{2}=\left[a_{2} e^{k t}\left(t-\frac{1}{k}\right)\right]_{t=T}-\left[a_{2} e^{k t}\left(t-\frac{1}{k}\right)\right]_{t=0}
$$

Now replacing equation 10 and 11 into equation 9:

$$
\begin{gathered}
P V=P V_{1}+P V_{2}=\left[\frac{a_{1} e^{k t}}{k}+a_{2} e^{k t}\left(t-\frac{1}{k}\right)\right]_{t=T}- \\
{\left[\frac{a_{1} e^{k t}}{k}+a_{2} e^{k t}\left(t-\frac{1}{k}\right)\right]_{t=0}}
\end{gathered}
$$

\subsection{Seasonal Flows}

In this case, the cash flows behavior is described by the functional form $C F(t)=a_{1}+a_{2} \sin \left[a_{3}\right.$ $\left.\left(\mathrm{t}+a_{4}\right)\right]$, where $a_{1}, a_{2}, a_{3}$ and $a_{4}$ are constant. Thus,

$$
P V=\int_{0}^{T}\left\{a_{1}+a_{2} \sin \left[a_{3}\left(t+a_{4}\right)\right]\right\} e^{k t} d t
$$

Again, the integral indicated in equation 13 can be segmented in two parts:

$$
P V=P V_{1}+P V_{2}=a_{1} \int_{0}^{T} e^{k t} d t+a_{2} \int_{0}^{T} \sin \left[a_{3}\left(t+a_{4}\right)\right] e^{k t} d t
$$

$P V_{1}$ may be calculated using the procedures indicated in subsection 3.1. In order to calculate the second part $\left(P V_{2}\right)$ the algebraic procedure indicated below is required:

$P V_{2}=a_{2} \int_{0}^{T} \sin \left[a_{3}\left(t+a_{4}\right)\right] e^{k t} d t$

$\sin \left[a_{3}\left(t+a_{4}\right)\right]=\sin \left(a_{3} t+a_{3} a_{4}\right)=\sin \left(a_{3} t\right) \cos \left(a_{3} a_{4}\right)+\cos \left(a_{3} t\right) \sin \left(a_{3} a_{4}\right)$

$\cos \left(a_{3} a_{4}\right)=c t e=d_{1}$

$\sin \left(a_{3} a_{4}\right)=$ cte $=d_{2}$

$\sin \left[a_{3}\left(t+a_{4}\right)\right]=d_{1} \sin \left(a_{3} t\right)+d_{2} \cos \left(a_{3} t\right)$

$P V_{2}=a_{2} \int_{0}^{T} \sin n\left[a_{3}\left(t+a_{4}\right)\right] e^{k t} d t=a_{2} \int_{0}^{T} d_{1} \sin \left(a_{3} t\right) e^{k t} d t+a_{2} \int_{0}^{T} d_{2} \cos \left(a_{3} t\right) e^{k t} d t$ $P V_{2}=a_{2} d_{1} \int_{0}^{T} \sin \left(a_{3} t\right) e^{k t} d t+a_{2} d_{2} \int_{0}^{T} \cos \left(a_{3} t\right) e^{k t} d t$

The two parts of the right side of equation 15 are calculated below (see Spiegel \& Liu, 1999, p. 85 , eq. 14.518 e 14.519$)$ :

$$
\begin{aligned}
& P V_{2}=a_{2} d_{1} \int_{0}^{T} \sin \left(a_{3} t\right) e^{k t} d t+a_{2} d_{2} \int_{0}^{T} \cos \left(a_{3} t\right) e^{k t} d t \\
& P V_{2}=a_{2} d_{1}\left\{\frac{e^{k t}\left[k \sin \left(a_{3} t\right)-a_{3} \cos \left(a_{3} t\right)\right]}{k^{2}+a_{3}^{2}}\right\}+a_{2} d_{2}\left\{\frac{\left.e^{k t}\left[k \cos \left(a_{3} t\right)-a_{3} \sin \left(a_{3} t\right)\right]\right]}{k^{2}+a_{3}^{2}}\right\}
\end{aligned}
$$

Now replacing equations 9 and 16 and the definitions of $d_{1}$ and $d_{2}$ into equation 14 , the result below can be obtained: 


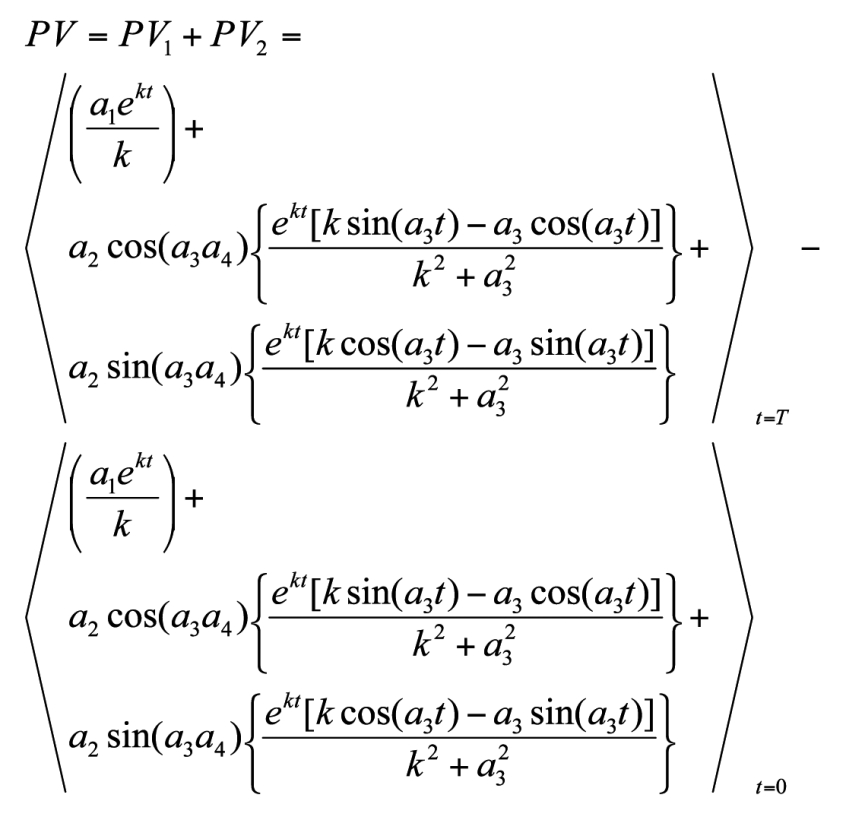

(17)

\section{Implications}

The results obtained in the previous section, though apparently hard, have a series of practical implications for the investment appraisal analysis. In order to figure out these implications, we consider a "stylized example" of cash flow of \$ 100.00 and compare the present values calculated using both discrete and continuous cash flow distribution.

The first implication is that the assumption of continuously distributed cash flows leads to a present value $P V_{\text {const }}$ greater than the one that would be obtained if the cash flows were supposed to discretely concentrate at the end of the period $\left(P V_{\text {disc }}\right)$. Thus, if, for example, $C F(t)=\$ 100.00$ and $r=10 \%$, the present value obtained for the interval between 0 and 1 is given by $P V_{\text {const }}$ below

$$
\begin{aligned}
& P V_{\text {const }}=\left(\frac{a_{1} e^{k t}}{k}\right)_{t=1}-\left(\frac{a_{1} e^{k t}}{k}\right)_{t=0} \\
& P V_{\text {const }}=\left(\frac{100 e^{1,1 x 1}}{1.1}\right)-\left(\frac{100 e^{1,1 x 0}}{1.1}\right)=95.38
\end{aligned}
$$

The value obtained above is smaller than the accumulated (not discounted) cash flow at the end of the period ( $\$ 100.00$ ), but smaller than the discounted value considering a discrete distribution of the cash flows $\left(P V_{\text {disc }}=\$ 90.91\right)$. Basically, in this case, cash flows originally assumed to occur only at the end of the period are computed earlier, so that the present value reaches a higher value.

These results, as well as the other ones mentioned in this paper, are indicated in table 1 below. The difference between $P V_{\text {disc }}$ and $P V_{\text {const }}$ - which in this case is around 5\% - tends to increase as higher discount rates are used. In fact, for $r=$ $20 \%$, the percentage difference between these two values reaches almost $9 \%$. Thus, in this case, it is clear that assuming that the cash flows concentrate at the end of the period - instead of assuming their continuous distribution over time - may turn an attractive investment (i.e., and investment for which the actual NPV >0) to be rejected as its underestimated NPV may be smaller than zero.

In the case of linear cash flows, the magnitude of the difference between $P V_{\text {disc }}$ and $P V_{\text {const }}$ depends on the increasing or decreasing path followed by the cash flows during the period. Thus, assuming, for example, that the yearly instantaneous cash flows between $t=0$ and $t=1$ move up from $\$ 50.00$ to $\$ 150.00$ (i.e., $C F(t)=50.00$ $+100.00 t$ ) so that the accumulated cash flows at the end of the period would reach $\$ 100.00$, the difference between $P V_{\text {disc }}$ and $P V_{\text {const }}$ would reach around $4 \%$. However, the same accumulated end-of-period cash flow of \$ 100 in a decreasing path of the yearly instantaneous cash flows moving from $\$ 150$ to $\$ 50$, for example $(C F(t)$ $=150.00-100.00 t$ ), would raise the difference between $P V_{\text {disc }}$ and $P V_{\text {const }}$ to more than $5 \%$. These results in fact reflect common sense: in the first case, the larger cash flows are closer to the end of the period and the error of assuming that all of the cash flows concentrate at that moment is 
smaller than the error when the larger cash flows are closer to the beginning (and not the end) of the period. Again, the difference between $P V_{\text {disc }}$ and $P V_{\text {const }}$ tends to increase as higher discount rates are used. For $\mathrm{r}=20 \%$, for example, the errors, in the two cases indicated in this paragraph, move up to around $7 \%$ and $10 \%$, respectively (Table 1 ).

Table 1: Differences between $P V_{\text {disc }}$ and $P V_{\text {const }}$

\begin{tabular}{|c|c|c|c|c|c|c|}
\hline & & Constant & $\begin{array}{c}\text { Linear } \\
\text { (increasing) }\end{array}$ & $\begin{array}{c}\text { Linear } \\
\text { (decreasing) }\end{array}$ & $\begin{array}{l}\text { Seasonal } \\
\text { (sine) }\end{array}$ & $\begin{array}{l}\text { Seasonal } \\
\text { (co-sine) }\end{array}$ \\
\hline \multirow{3}{*}{$\frac{\text { 웅 }}{\stackrel{1}{I I}}$} & $P V_{\text {const }}$ & 95.38 & 94.62 & 96.14 & 96.11 & 94.66 \\
\hline & $P V_{\text {disc }}$ & 90.91 & 90.91 & 90.91 & 90.91 & 90.91 \\
\hline & Difference & $4.69 \%$ & $3.93 \%$ & $5.44 \%$ & $5.41 \%$ & $3.96 \%$ \\
\hline \multirow{3}{*}{$\begin{array}{l}\stackrel{0}{0} \\
\text { } \\
\text { II } \\
-\end{array}$} & $P V_{\text {const }}$ & 91.41 & 90.03 & 92.80 & 92.74 & 90.09 \\
\hline & $P V_{\text {disc }}$ & 83.33 & 83.33 & 83.33 & 83.33 & 83.33 \\
\hline & Difference & $8.84 \%$ & $7.43 \%$ & $10.20 \%$ & $10.14 \%$ & $7.50 \%$ \\
\hline
\end{tabular}

Source: Elaborated by the author.

In the case of seasonal cash flows, the conclusion that the difference between $P V_{\text {disc }}$ and $P V_{\text {const }}$ is smaller when larger cash flows are closer to the end of the period remains valid. A numerical example illustrates the results for $C F(t)=$ $a_{1}+a_{2} \sin \left[a_{3}\left(\mathrm{t}+a_{4}\right)\right]$ where $a_{1}=100$ (i.e., the cash flows oscillate around 100) and $a_{2}=50$ (so that the cash flows range from 50 to 150 during the period). If between $t=0$ and $t=1$ the functional form presents a sine periodic behavior (i.e., the peak of the cash flows is closer to the beginning than to the end of the period), the difference between $P V_{\text {disc }}$ and $P V_{\text {const }}$ is of around $5 \%$; on the other hand, if the functional form is a half period delayed (so that it seems like a cosine function as indicated in graph 1), the difference reduces to less than $4 \%$ (table 1 ).

\section{Concluding remarks}

In this paper, we compared the net present value of a typical investment considering both a discrete distribution of expected cash flows and a continuous one. Three possibilities for the continuous cash flow distribution were examined: $i)$ expected cash flows are equivalent to an annuity, ii) expected cash flows are equivalent to an annuity and with a linear distribution pattern over time and iii) expected cash flows are equivalent to an annuity but with a seasonal distribution pattern. As shown in section 2 , the use of different patterns of cash flow distribution is a theoretical contribution of this paper, as previous works such as Ismail \& Cline (2005) focus only on a single functional form to describe the behavior of continuous cash flows inside each period.

Two main conclusions can be highlighted after the analysis carried out in this paper:

There might be significant differences between the present values calculated assuming discrete cash flows concentrated at the end of each period and assuming continuous cash flows distributed throughout the whole period. Differences can easily surpass $5 \%$.

Differences increase as the discount rates increase. This conclusion suggests that riskier projects for which the weighted average capital costs are higher are particularly sensitive to the assumptions of discrete or continuous cash flows used to discount their expected cash flow generation. In such cases, as shown in table 1 , differences can easily surpass $10 \%$.

At any rate, investment appraisal techniques must consider how adherent the functional forms chosen for the cash flows are to the reality they are intended to represent. Besides, the functional forms discussed in section 3 - and any other functional form that may be used to represent the cash flows $C F(t)$ - are analytical, continuous 
and differentiable, as opposed to models which assume discrete cash flows. That explains why continuous cash flow discount is widely used in real options and theoretical approaches but hardly mentioned in the discussion of investment appraisal finance textbooks. Besides, on most circumstances, discrete cash flows are used just because it is easier to compute them as compared to continuous cash flows.

However, in face of the errors that may result from an inadequate assumption of discrete cash flows, it might be questioned why the assumption of discrete cash flows concentrated at the end of each period remains widely used. Of course, a possible reason is purely didactic and has to do with the simple fact that it is easier to discount discrete cash flows than to discount continuous cash flows using more complex models. This explanation, however, does not seem enough to justify the use of (inadequate) discrete models in the appraisal of actual investment projects, especially because widely available computer programs and spreadsheets can deal with the calculation of continuous discounting. Another possible explanation is the option for more conservative results. As the assumption of positive cash flows concentrated at the end of each period - instead of continuously distributed on time - tends to reduce the present value and the net present value of the project as a whole, the investment appraisal would lead to a more conservative decision. In other words: if NPV turns out to be positive even if cash flows are wrongly assumed to happen after their true moment of occurrence, the project is to be accepted. This somewhat troubling explanation seems too naïve, especially when one takes into account the efforts to compute cash flows and capital costs in a more precise and realistic way. Expensive and complex efforts to estimate the capital costs, for example, might be irrelevant if errors are deliberately introduced in the cash flow discount procedures.

It must be pointed out, however, that on some occasions, the assumption of discrete cash flows concentrated at the end of each period may be more realistic than the assumption of continuously distributed cash flows. In fact, some firms produce goods and buy raw materials just at some specific moments in time. For example, shipyards and aircraft manufacturers have cash flows related to contracts usually associated to discrete moments. Besides, fiscal and accounting aspects may cause inflexions in cash flow behavior. Dividends and taxes are not paid continuously. Many taxes are paid on a monthly or yearly basis, so that the assumption of continuous cash flows, in this case, is just wrong. As a result, operational, fiscal and accounting reasons must be taken into account when deciding the best way to discount cash flows in a specific investment appraisal.

In short, a more careful look on the patterns of distribution of cash flows on time may certainly lead to a more precise calculated NPV and to better decision making, which is, ultimately, what finance textbooks care about. The approaches discussed in this paper may contribute not only to better investment decisions when cash flows are (at least partially) continuously distributed, but also to the teaching literature on investment decisions.

\section{References}

Brealey, R. A. \& Myers, S. C. (1988). Principles of corporate finance. Boston: McGraw-Hill.

Brigham, E. F. \& Houston, J. F. (2004). Fundamentals of financial management. Mason (Ohio): Thomson South Western.

Copeland, T. \& Antikarov, V. (2002). Opções reais. Rio de Janeiro: Campus. 
Chiang, A. C. \& Wainwright, K. (2009). Fundamental methods of mathematical economics. Boston, Mass.: McGraw-Hill.

Damodaran, A. (1998). Applied corporate finance: a user manual. New York: John Wiley \& Sons.

Dixit, A. K. \& Pindyck, R. S. (1994). Investments under uncertainty. New Jersey: Princeton University Press.

Garrett, S. J. (2013). An introduction to the mathematics of finance: a deterministic approach (2nd ed.) Waltham (MA): Institute and Faculty of Actuaries / Elsevier.

Gitman, L. J. (1997). Princípios de administração financeira. São Paulo: Harbra.

Ismail, T. \& Cline, M. (2005). Investment appraisal under conditions of continuous and discrete cash flow and discounting. Managerial Auditing Journal, 20 (1), $30-35$.
Jones, T. W. \& Smith, D. J. (1982). An historical perspective of net present value and equivalent annual cost. The Accounting Historians Journal, 9(1), 103-110.

Pogue, M. (2004). Investment appraisal: a new approach. Managerial Auditing Journal, 19(4), 565-569.

Ross S. A., Westerfield, R. W. \& Jaffe, Jeffrey F. (1995). Administração financeira. São Paulo: Atlas.

Spiegel, M. R. \& Liu, J. (1999). Mathematical handbook of formulas and tables (McGraw-Hill international editions / Schaum's outline series). Boston: McGraw Hill Professional.

Trigeorgis, L. (1996). Real options: managerial flexibility and strategy in resource allocation.

Cambridge: The MIT Press.
Recebido em 7 dez. 2017 / aprovado em 13 mar. 2018

Para referenciar este texto

Cavalcante, L. R., \& Rocha, C. H. Investment appraisal and the choice between continuous and discrete cash flow discounting. Exacta, São Paulo, v. 16, n. 4, p. 125-134. out./dez. 2018. Disponível em: <https://doi.org/10.5585/ExactaEP.v16n4.8143> 